\title{
Health claims within the Swedish Code
}

\section{Generic claims and product-specific physiological claims in relation to current European and international developments}

\section{Nils-Georg Asp*}

Applied Nutrition and Food Chemistry, Center for Chemistry and Chemical Engineering, Lund University, Lund, Sweden, and SNF, Swedish Nutrition Foundation

\begin{abstract}
"Functional food" continues to be a highly interesting and much debated issue, with regard to scientific support, business potential, and importance for health and well-being. Problems with delimiting the concept can be overcome by regarding functional foods as foods with health claims. Various types of claim then have to be defined, as well as requirements for their scientific documentation. Such definitions are currently emerging internationally within Codex Alimentarius and within the European Commission. Guidelines on scientific substantiation have been issued within the Council of Europe, and the development of criteria for the scientific support of claims is focused on within the EC Fifth Framework concerted action project "Process for the Assessment of Scientific Support for Claims" (PASSCLAIM). The Swedish Code on health claims, effective since 1990 regarding generic claims in two steps and extended in 2001 to "product-specific physiological claims", is in line with these developments.
\end{abstract}

Keywords: Functional foods, health benefits, substantiation of claims.

Received: 15 August 2002; Accepted: I September 2002

\section{What is functional food?}

The concept of functional foods has led to an increasing interest in developing foods with optimal properties in promoting health, well-being and performance, from the point of view of public health as well as business opportunities for the food industry. It has been suggested to be an important step from traditional to new concepts in nutrition; as progress from a concept of "adequate nutrition" to one of "optimal nutrition" (1).

Various working definitions have been proposed, all implying that functional foods have scientifically supported health benefits in addition to their basic nutritional value. The European Union (EU) concerted action project "Functional Food Science in Europe" (FUFOSE) described the state of the art regarding food-related nutrition research in various fields relevant to the development of functional foods. Several key target functions were

* MD, Prof., Director, SNF Swedish Nutrition Foundation. defined, related to (i) growth, development and differentiation, (ii) substrate metabolism, (iii) defence against oxidative species, (iv) the cardiovascular system, (v) intestinal physiology, and (vi) behavioural and psychological functions (2). In all of these fields, recent scientific progress was defined as a basis for functional food development.

A working definition was worded within the FUFOSE project as follows: "A food can be regarded as 'functional' if it is satisfactory demonstrated to affect beneficially one or more target functions in the body, beyond adequate nutritional effects, in a way that is relevant to either an improved state of health and well-being and/or reduction of disease risk" (1). Strictly interpreted, such a definition would restrict functional foods to products that have been demonstrated, through human intervention studies, to have specific physiological effects in addition to providing basic nutrients, i.e. products eligible for product-specific claims (see below). In practice, however, "functional food" is generally used as a wider concept for foods with health-related added value, including foods 
enriched or fortified with vitamins and minerals, foods with low fat content and/or modified fatty acid composition, and high-fibre products, as well as innovative foods demonstrated by human intervention studies to provide specific beneficial effects when consumed as part of a normal, nutritionally adequate diet.

One way to overcome the need for an exact definition and delimitation of functional food is to regard functional foods as foods with health claims, and then to define different types of claims and requirements for their scientific substantiation.

\section{The Swedish Code}

The Swedish Code on health claims, entitled "Health Claims in the Labelling and Marketing of Food Products, The Food Industry's Rule (SelfRegulating Programme)" was introduced in 1990. The use of health claims in the labelling and marketing of foods became possible when the National Board of Health and Welfare and Drug Department (now the Medicinal Products Agency) decided in 1989 to stop applying medicinal product legislation "to products commonly found on the dinner table; the condition being that no dosage be given in marketing the product and that no information be given which is used for medicinal products, e.g. tablets or capsules, even if they consist of raw materials generally used for foodstuffs" (3).

A health claim was defined in the original Swedish Code from 1990 as "an assessment of the positive health effects of a foodstuff, i.e. a claim that the nutritional composition of the product can be connected with prophylactic effects or the reduced risk of a diet-related disease". The following general requirements were stated: "The health claim must be based on the importance of the product in a balanced diet, and must be in line with official Swedish dietary recommendations". In the revised version of the Code from 1997, the two-step principle was explicitly required: "The claim must consist of two parts: information on diet-health relationship, followed by information on the composition of the product" (3).

The Code lists eight different generally recognized diet-health relationships around which generic health claims can be used:

- obesity: energy content

- cholesterol level in the blood: fat quality or some soluble dietary fibre

- blood pressure: salt (sodium chloride)
- atherosclerosis: blood cholesterol level/blood pressure, n-3 (omega-3) fatty acids in fat fish and fish products

- constipation: dietary fibre

- osteoporosis: calcium

- caries: absence of sugars and other fermentable carbohydrates

- iron deficiency: iron content.

These connections are closely related to the official nutrition recommendations.

In a revision of the programme, applicable from 1997, the two-step principle was explicitly required by the authorities for continued reference to the programme. "Health claims must be formulated in two parts, i.e. information on the diet-health relationship, followed by information on the composition of the product" (3). The Swedish Nutrition Foundation (SNF) has an advisory and co-ordinating role in the Swedish Code.

In 1998 the responsible organizations behind the Code - now the Swedish Cooperative Union, the Federation of Swedish Farmers, the Swedish Food Federation, the Swedish Federation of Trade and the Swedish Grocers' Federation - and the SNF made a proposal to extend the programme to product-specific physiological claims (4). The need for such an extension was anticipated in the revised programme in view of the developments within the area of functional foods. The proposed extension included the requirement of human intervention studies to support the claim, showing the effect at normal consumption of the product, and that these studies be evaluated prior to marketing by independent experts. Another part of the proposal was establishment of a separate Assessment Board for Diet-Health Information to handle any complaints regarding the application of the Code.

Having received support from the Swedish Consumers' Association and the Swedish Consumer Coalition, and a positive response on presentation to the Department of Agriculture and the National Food Administration, the extended Code was applied from September 2001. The SNF was assigned to organize the pre-market expert evaluations of the scientific documentation, and the Assessment Board for Diet-Health Information was constituted in November 2001 (5).

\section{Definitions of health claims}

\section{Different types of health-related claim}

Definitions of health claims are currently being developed within the Codex Alimentarius Com- 
Table I. Comparison of different types of claims according to Codex Alimentarius (6), Council of Europe (7), the Swedish Code on Health Claims (3, 4) and the EC Concerted action project FUFOSE (I)

\begin{tabular}{|c|c|c|c|c|}
\hline & Codex Alimentarius & $\begin{array}{l}\text { Council of Europe } \\
\text { Guidelines }\end{array}$ & Swedish Code & FUFOSE \\
\hline Type of health claim & $\begin{array}{l}\text { Proposed draft guidelines, Step } 5 \\
\text { of the Procedure } 2002\end{array}$ & $\begin{array}{l}\text { Technical Document } \\
2001\end{array}$ & $\begin{array}{l}\text { Original Code } 1990 \text {, revised } 1997, \\
\text { extended to "PFP" } 1998 / 2001\end{array}$ & $\begin{array}{l}\text { EC Concerted Action: } \\
\text { Functional Food Science in } \\
\text { Europe } 1999\end{array}$ \\
\hline "Normal" functions of nutrients & Nutrient function claims & - & $\begin{array}{l}\text { Nutrient function claims } \\
\text { (commented briefly) }\end{array}$ & - \\
\hline $\begin{array}{l}\text { Functions of non-nutrients or } \\
\text { "extra" function of nutrients }\end{array}$ & $\begin{array}{l}\text { (Other) Function claims; } \\
\text { previously Enhanced function } \\
\text { claims }\end{array}$ & $\begin{array}{l}\text { Enhanced function } \\
\text { claims }\end{array}$ & $\begin{array}{l}\text { Product-specific physiological } \\
\text { claims (PFP) }\end{array}$ & $\begin{array}{l}\text { Enhanced function claims } \\
\text { (type A) }\end{array}$ \\
\hline $\begin{array}{l}\text { Reduction of disease risk, usually } \\
\text { by effect on risk factors }\end{array}$ & $\begin{array}{l}\text { Reduction of disease risk claims } \\
\text { (in two parts) }\end{array}$ & $\begin{array}{l}\text { Reduction of disease } \\
\text { risk claims }\end{array}$ & $\begin{array}{l}\text { Health claims in two parts: } \\
\text { I. diet-health relation } \\
\text { 2. composition of product }\end{array}$ & $\begin{array}{l}\text { Reduction of disease risk claims } \\
\text { (type B) }\end{array}$ \\
\hline
\end{tabular}

mission, Codex Committee on Food Labelling. The three different types of health-related claim defined at present are listed in Table 1. Codex Alimentarius defines a nutrition claim as any representation that states, suggests or implies that a food has particular nutritional properties. A health claim is defined as "any representation that states, suggests, or implies that a relationship exists between a food or a constituent of that food and health". Health claims are suggested to include the following categories (6):

- nutrient function claims: a nutrition claim that describes the physiological role of the nutrient in growth, development and normal functions of the body

- (other) function claims (previously enhanced function claims): these claims concern specific beneficial effects of the consumption of food and their constituents in the context of the total diet on physiological (or psychological) functions or biological activities, but do not include nutrient function claims. Such claims refer to a positive contribution to health or to the improvement of a function or modifying or preserving health

- reduction of disease risk claims: claims relating the consumption of a food or a food constituent, in the context of the total diet, to the reduced risk of developing a disease or healthrelated condition.

Within the Council of Europe, Partial Agreement in the Social and Public Health field, a technical document, "Guidelines concerning the scientific substantiation of health-related claims for functional foods", was published in 2001 (7). This document provides guidance on the scientific substantiation of two types of health-related claim: "enhanced function" and "reduction of disease risk". These definitions are in agreement with those originally suggested within the FUFOSE project (enhanced function claims $=$ type $\mathrm{A}$ and disease risk reduction claims = type $\mathrm{B}$ ). The product-specific physiological claims (abbreviated "PFP" in Swedish) and the generic two-step claims listed in the original Swedish Code correspond to type A and B claims, respectively.

\section{Generic and product-specific claims}

The Council of Europe document makes another important differentiation between generic and product-specific claims (Table 2), worded as follows: "Generic claims are based on a consensus in the scientific community regarding a diet-disease relationship. The claim can be used for any product provided that it fulfils certain compositional criteria. Product specific claims, on the other hand, imply that the food product per se has certain physiological effects when the food product is consumed in realistic amounts" (7). A clear differentiation has been made between generic and product-specific claims in the Swedish $(3,4)$ and UK (8) codes, as well as in reports from Health Canada $(9,10)$ and the Australian New Zealand Food Authority (11). This differentiation is important from several points of view.

Generic claims are based on generally accepted diet-health interactions. They are applicable to all food products that fulfil certain compositional criteria, e.g. a high content of calcium, dietary fibre or another nutrient, or a low content of saturated fat. Human intervention studies with the particular 


\begin{tabular}{|c|c|}
\hline Generic claim & Product-specific claim \\
\hline \multicolumn{2}{|l|}{ Nutrient function claim } \\
\hline \multicolumn{2}{|l|}{$\begin{array}{l}\text { e.g. Calcium is important for developing strong bones. Product } X \text { is a good source } \\
\text { of calcium }\end{array}$} \\
\hline & Enhanced function claim \\
\hline $\begin{array}{l}\text { e.g. Inulin promotes absorption and utilization of calcium in the body. Product } \\
X X \text { is a good source of inulin }\end{array}$ & $\begin{array}{l}\text { e.g. Product } X Y \text { improves utilization of calcium in the body } \\
\text { (active component inulin) }\end{array}$ \\
\hline \multicolumn{2}{|l|}{ Reduction of disease risk claim } \\
\hline $\begin{array}{l}\text { e.g. As part of a low-fat, high fibre diet, calcium is important, together with } \\
\text { physical exercise, to make strong bones and diminish the risk of fractures. } \\
\text { Product } \mathrm{YX} \text { is a good source of calcium that is well utilized in the body }\end{array}$ & $\begin{array}{l}\text { (As part of a healthy diet, daily consumption of two } \\
\text { servings of } Y Y \text { helps to diminish the risk of fractures) }\end{array}$ \\
\hline
\end{tabular}

Nutrient function claims are by definition generic. Enhanced function claims are basically product specific. Enhanced (Other) function claims may become generic ( $\longrightarrow$ ) when the active component has been demonstrated to retain its physiological effect regardless of the food vehicle in which it is incorporated. Reduction of disease risk claims are basically generic, but might in certain cases become product-specific $(\longrightarrow)$.

product are not required to substantiate the claim.

Product-specific claims are based primarily on human intervention studies showing that consumption of the product as part of a normal diet provides the claimed physiological effect.

The original Swedish Code was limited to generic claims, whereas the extension addresses "product-specific physiological claims", corresponding to product-specific enhanced function claims.

Nutrient function claims, corresponding to "functional claims" as defined in the recent draft proposal from the European Commission (12), are by definition generic since they relate to generally accepted knowledge about the function of a food or food constituent.

Enhanced function claims, i.e. "specific beneficial effects of foods, nutrients, components or ingredients on physiological, psychological functions or biological activities beyond their established role in growth, development and other normal functions of the body" (7) or "a specific beneficial effect beyond that normally obtained from the diet" (12), refer primarily to effects demonstrated for a certain food product, i.e. a product-specific claim. However, once an innovative active component has been shown to be effective regardless of the food vehicle containing it, there is a basis for a generic function claim concerning that component. The two-step principle is useful for such claims, as well as for reduction of disease risk claims.

In the recent Codex proposed draft guidelines (6), the example given for (other) function claims is, in fact, such a generic two-step claim related to a function of an active ingredient. Regarding reduction of disease risk claims, the two-step princi- ple is mandatory, provided that the disease risk can be linked to a specific constituent of the food.

\section{Scientific substantiation of claims}

Guidelines for the scientific substantiation of claims have been developed mainly regarding product-specific claims. The Council of Europe document (7) mentions, as general guidelines, that the final substantiation of a health-related claim should be made on the food product as it will be offered to the consumer. The substantiation should (i) rely on the totality of evidence, (ii) be plausible in terms of basic scientific knowledge and biological mechanisms of the effects, (iii) be plausible in the relationship between the intervention and the results, (iv) be corroborated by several sources that in most cases include human intervention studies, and (v) be able to meet accepted scientific standards of both statistical and biological significance.

Among the specific guidelines mentioned, it is stated that the required human intervention studies should be repeated at least once, in a different laboratory (7).

\section{The Swedish Code}

According to the Swedish Code extended to product-specific physiological claims, the studies on which the claim is based "must be performed on human beings, and the study group must be representative of the target group for the marketing". Furthermore, "the studies must be performed with a supply relating to the normal use of the food product during the study period, and must be long enough to show a lasting effect". The number of studies required is determined on a case-by-case 
basis, depending on how well established the expected effect is, and depending on the type and size of the studies performed with the product. When the scientific documentation has been evaluated, the product can be marked with a special logotype, as shown in Fig. 1. Reference is made to the homepage of the Code (http://www.hp-info.nu).

The eight approved connections listed in the Swedish Code as the basis for generic claims in two steps are directly related to the official nutrition recommendations. A general requirement is that the claims "must be formulated to take into account the need for a balanced diet providing all the different nutrients". Furthermore, "such claims should only be made in the marketing of products, the normal consumption of which has a substantial effect on the diet as a whole" (3). This means that generic claims can be applied to all products fulfilling certain compositional criteria. The product should be a substantial source of the nutrient mediating the diet-health effect, or have a low or reduced content of, for example, saturated fat or salt. Human effect studies with the product are not required.

\section{The PASSCLAIM project}

Criteria for the scientific substantiation of claims are further developed within the EC concerted action project "Process for the Assessment of Scientific Support for Claims on Foods" (PASSCLAIM) (13). The overall objective is to produce a consensus on principles for the scientific substantiation of health-related claims. Criteria for how markers should be identified, validated and used are an important aspect of the project. The PASSCLAIM project engages about 70 European scientists from universities, institutes and industry, and the definition of science-based criteria for the substantiation of health-related claims is expected to contribute substantially to the development of harmonized requirements for the scientific substantiation of various types of claim.

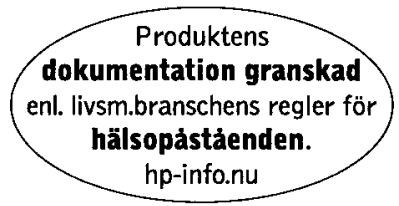

Fig. 1. Logotype to be used on products that have passed the evaluation of scientific documentation according to the extended Swedish Code. The Swedish text means: "Product with documentation evaluated according to the food sector's rules regarding health claims".

\section{Nutritional safety}

A food product bearing a health claim must be safe. This is a basic requirement for all foods, and especially relevant for a "functional food", intended to be consumed regularly during a long period. In addition, the general nutritional composition should be such that the food fits into and contributes to a generally nutritious and balanced diet. The Council of Europe document uses the expression "nutrition safety" and states that, in addition to traditional risk assessment, "nutrition safety also needs to be taken into consideration". Products for which health-related claims are made should "Fit into a nutritionally adequate diet" and "Not be in conflict with national nutrition policies" (7).

The Swedish Code requires that foods eligible for product-specific physiological claims "should through their composition contribute positively to a nutritionally adequate diet". Nutrition labelling comprising eight nutrients (group 2) is required (5). Products with health claims should not counteract the general dietary guidelines, although it is recognized that definition of criteria in this respect is needed and may sometimes be difficult.

\section{Towards a harmonized European regulation}

In June 2002 the European Commission issued a proposed draft regulation on nutrition, functional and health claims for comments (12). The recognition that food can promote health and decrease the risk of disease, distinct from the preventive effects of medicinal products, is an important prerequisite for health-related claims for foods. The principles for different types of claim and their scientific substantiation are well in line with the developments within Codex and the Council of Europe document described above, as well as the voluntary codes now operating in Sweden, the UK (8) and the Netherlands (14). It is important to differentiate clearly between generic and product-specific claims. Generic claims are based on generally accepted knowledge and do not require human studies with the food product to document a physiological effect, whereas such studies form the core documentation behind product-specific claims.

\section{References}

1. Diplock AT, Aggett PJ, Ashwell M et al: Scientific concepts of functional foods in Europe: Consensus Document. Br J Nutr 1999;81:S1-S19.

2. Bellisle F, Diplock AT, Hornstra $G$ et al: Functional food science in Europe. Br J Nutr 1998;80 (Suppl. 1): $\mathrm{S} 1-\mathrm{S} 193$. 
3. Swedish Nutrition Foundation. Health claims in the labelling and marketing of food products. The food industry's rules (self-regulating programme) SNF, Ideon, SE-22370 Lund, Sweden.

4. Swedish Nutrition Foundation: Proposal for extension of the Swedish Code on health claims to functional food products. Scand J Nutr 1998;42:119.

5. Asp N-G, Trossing M: The Swedish code on health-related claims in action - extended to product-specific physiological claims. Scand J Nutr 2001;45:189-91 (http://www.snf.ideon.se/snf/en/rh/401-189-192eng. gransk.pdf).

6. Codex Alimentarius Commission. Codex Committee on Food Labelling. Proposed draft recommendations for use of health and nutrition claims. ALINORM 2002; 03/22, Appendix VII.

7. Council of Europe. Technical document. Guidelines concerning scientific substantiation of health-related claims for functional food, 2 July 2001 (www.coe.fr/ soc-sp).

8. Joint Health Claims Initiative. UK Code of Practice on health claims on foods, 2000 (http://www.jhci.co.uk).

9. Health Canada. Consultation Document: Standards of evidence for evaluating foods with health claims. A proposed framework. Ottawa: Health Canada; 2000 (http:/www.hc-sc.gc.ca/food-aliment/English/subjects/ health_claims/Consultation_doc_en.pdf).
10. Health Canada. Product-specific authorization of health claims for foods. A proposed regulatory framework. Ottawa: Health Canada; October 2001.

11. Australia New Zealand Food Authority. Review of health and related claims, full assessment report proposal P153 and pilot for management of framework for health claims draft inquiry report proposal P170. ANZFA Canberra and Wellington; 2000 (http:/www. anzfa.gov.au /documents/information_circular_02-01/ p153.pdf).

12. Commission of the European Communities. Draft proposal for regulation of the European Parliament and of the Council on nutrition, functional and health claims made on foods. Working document SANCO/1832/2002.

13. PASSCLAIM - Process for the Assessment of Scientific Support for Claims on Foods. European Commission concerted action organized by ILSI Europe; 2002 (http: //europe.ilsi.org).

14. Netherlands Nutrition Centre. Code of practice assessing the scientific evidence for health benefits stated in health claims on food and drink products; 1998 (http:// www.voedingscentrum.nl).

Nils-Georg Asp, MD., Ph.D. Prof.

SNF Swedish Nutrition Foundation, Ideon Research Park, SE-223 70 Lund, Sweden

Email: asp@snf.ideon.se

\section{First evaluation completed according to the extended Swedish Code on health claims}

The first evaluation of the scientific documentation behind a product-specific physiological claim has been completed and the product is now on the market. It is a yoghurt product with a muesli rich in beta-glucans from oats. The expert panel, appointed by the research committee of the SNF
Swedish Nutrition Foundation, concluded that the documentation supports a claim that the product lowers, smooths out or attenuates the blood glucose level after a meal. The expert report is available at the home page of SNF (www.snf.ideon.se). 